\title{
Personality and Subjective Well-Being: What Hides Behind Global Analyses?
}

Article in Social Indicators Research · January 2013

DOI: 10.1007/s11205-010-9780-7 · Source: RePEc

CITATIONS

23

4 authors:

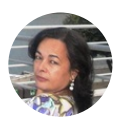

Isabel Albuquerque

University of Coimbra

10 PUBLICATIONS 58 CITATIONS

SEE PROFILE

\section{Marcela Matos}

University of Coimbra

76 PUBLICATIONS 840 CITATIONS

SEE PROFILE
READS

283

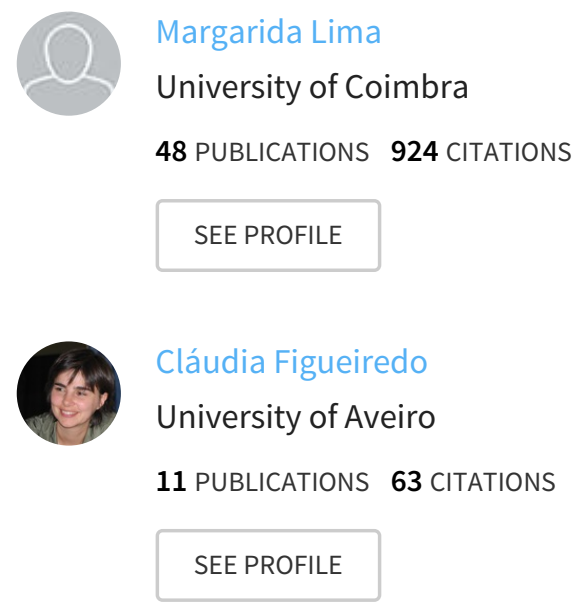

Some of the authors of this publication are also working on these related projects:

NoHoW - EVIDENCE-BASED ICT TOOLS FOR WEIGHT LOSS MAINTENANCE -- http://nohow.eu/ View project

Project $\quad$ Compassionate Schools View project 


\title{
Personality and Subjective Well-Being: What Hides Behind Global Analyses?
}

\author{
Isabel Albuquerque • Margarida Pedroso de Lima • \\ Marcela Matos • Cláudia Figueiredo
}

Accepted: 26 December 2010/Published online: 4 January 2011

(C) Springer Science+Business Media B.V. 2011

\begin{abstract}
The relation between personality and subjective well-being (SWB) remains involved in a considerable ambiguity and the numerous studies conducted have neglected an approach at a more detailed level of analysis. This study explores the idea that neuroticism, extraversion and conscientiousness facets predict differentially each SWB component. A battery of self-report questionnaires was used to assess personality and SWB in 398 teachers of primary and high schools. Findings of a cross-sectional study showed that neuroticism, extraversion and conscientiousness facets contributed to significantly explain the variance in positive affect, negative affect and life satisfaction. Moreover, these facets predicted differentially each of the three SWB components. At same time, this study corroborates two important premises: the specificity of facets as discrete traits and the independence of the three SWB components.
\end{abstract}

Keywords Personality · Traits · Subjective well-being

\section{Introduction}

During the last decades, we have witnessed the intersection between personality and subjective well-being research fields. Subjective well-being has indeed been considered as the ideal arena to explore the personality coherence problematic (Pavot et al. 1995).

In a literature review concerning the importance of personality predictive value to various constructs, Ozer and Benet-Martinez (2006) highlighted that personality is a strong predictor of subjective well-being (SWB) while contextual factors only show moderate contributions. However, Lucas (2008), in a review concerning personality and SWB

\footnotetext{
I. Albuquerque $(\bowtie) \cdot$ M. P. de Lima - C. Figueiredo

Faculty of Psychology and Educational Sciences, University of Coimbra, Rua do Colégio Novo,

Apartado 6153, 3001-802 Coimbra, Portugal

e-mail: ialbuquerque.ialbuquerque@gmail.com

M. Matos

Cognitive and Behavioral Research Centre (CINEICC), University of Coimbra, Coimbra, Portugal
} 
relations, concludes that it is still ambiguous whether each of the traits contributes with unique variance to the prediction of SWB.

\section{Personality Traits}

Recently, Roberts (2009) suggested that traits still maintain their importance, since they define, even if partially, how people experience the world and understand its development. Therefore traits are critical for understanding crucial social outcome and key components of human nature.

The most consistent model of the personality study relating to traits level is the Five Factor Model (Costa and McCrae 1994; Golberg 1990, 1993; McCrae and John 1992; John and Srivastava 1999) that describes five traits of stable personality characteristics that organize individual's differences in emotional and social life. McAdams (1995) argues that the Big Five appear as a broad and consensual description of the traits domain.

The Five Factor Model is defined as "a hierarchical organization of personality traits in terms of five basic dimensions: Extraversion, Agreeableness, Conscientiousness, Neuroticism, and Openness to Experience" (McCrae and John 1992, p. 175. Each five personality factor includes six facets that are supposed to measure a discrete trait and to contribute something above and beyond the five factors, since these facets contain valid specific variance (Costa and McCrae 1992). McCrae and Costa (2008, p. 285) consider "that an analysis that incorporates NEO-PI-R facets and their combinations can lead to detailed information that goes far beyond the five factors". Several others authors have equally suggested that the prediction of numerous variables could be improved by using facets instead of global Big Five dimensions (Ekehammar and Akrami 2007; Paunonen and Ashton 2001; Paunonen et al. 2003; Reynolds and Clark 2001).

Studies have emphasized that this personality structure emerges in different cultures (McCrae and Costa 1997), that there is a continuum in the medium level of the traits from adolescence to old age (McCrae et al. 1999) and that gender differences occur homogeneously in diverse cultures (Costa et al. 2001). These conclusions led McCrae and Costa (2003) to interpret personality traits as biological rooted dispositions that characterize the entire human species. Other authors (Hooker and McAdams 2003; Little 1996, 2008; Little and Joseph 2007; McAdams and Pals 2006) concerned with the study of the structure, functioning and coherence of personality share this conception of personality traits as basic more or less stable dispositions that explain part of our singularity, with genetic and evolutionary roots, and which influence is founded on neurophysiologic mechanisms.

\section{Subjective Well-Being}

In the past decades, SWB has emerged as one of the most prevalent concepts in happiness assessment, being perceived more as a general area of scientific interest rather than a single specific construct (Diener et al. 1999). SWB is a multidimensional entity that involves a cognitive component, concerning how we evaluate our life satisfaction, and an affective component, related to our positive or negative emotional reactions (Diener and Lucas 1999). Therefore, an operational definition of SWB should be interpreted to mean experiencing a high level of positive affect, a low level of negative affect and a high degree of satisfaction with one life (Deci and Ryan 2008; Diener 2000; Diener et al. 2005). This threefold structure has been empirically confirmed by several studies that have shown 
some degree of empirical independence between them (Albuquerque et al. 2011; ArthaudDay et al. 2005; Lucas et al. 1996).

Since the 60s, there has been a growing development in the study of SWB, evolving from an initial interest in bottom-up factors (e.g. social demographical variables, external events, situations) to an emphasis on top-down factors (psychological processes) (Diener et al. 1999). More recently, some authors (Lyubomirsky et al. 2005; Sheldon and Lyubomirsky 2004) argue that happiness is influenced by three principal factors: set point, circumstantial or contextual, and intentional activity factors. The set point is genetically determined and represents the happiness level experienced if the remaining two factors could be neutralized. The circumstances or contexts of life include the social demographic variables, but also the geographic and environmental variables, whereas intentional activity refers to the actions that people engage in their lives. A recent study on the etiology of SWB (Bartels and Boomsma 2009, p. 613) suggests that “....although it can be assumed that each individual has its, probably genetically determined, setpoint of SWB (Lykken 1999), influences of environmental factors unique to each individual are important”.

\section{The Relation Between Traits and Subjective Well-Being}

Since Costa and McCrae (1980) highlighted that happiness is associated with high levels of extraversion and low levels of neuroticism, the relation between traits and SWB has been persistently documented in various studies. Some researchers have suggested the existence of a set point in SWB that may only be disturbed for short periods of time (Lykken and Tellegen 1996; Lyubomirsky et al. 2005). According to these authors this relative stability in SWB levels reflects the influence of traits and seems to be confirmed in a recent study with twins (Weiss et al. 2008). Research has shown that all the Big Five domains are associated to "happiness" in different degrees (DeNeve and Cooper 1998; Diener et al. 1999; Gutiérrez et al. 2005; Hayes and Joseph 2003; Steel et al. 2008).

Furthermore, results suggest that extraversion and neuroticism are the traits more consistently correlated with SWB (Argyle 1999; Cheng and Furnham 2001; Diener and Lucas 1999; Gutiérrez et al. 2005; McCrae and John 1992; Vitters $\varnothing$ and Nilsen 2002). Nevertheless, conscientiousness has also exhibited replicable and moderately strong associations with SWB (Lucas 2008) and can be seen as an additional personality dimension relevant to its understanding (Hayes and Joseph 2003).

The two affective components of SWB (positive and negative affect) emerge persistently related to neuroticism and extraversion (Fujita 1991; Gutiérrez et al. 2005; Lucas and Fujita 2000; McCrae and John 1992). These results suggest that extraversion and neuroticism may be conceived as primary links between personality and SWB.

Concerning the relation between traits and cognitive component (life satisfaction), results from a longitudinal study along 17 years period (Fujita and Diener 2005) reveal that personality traits seem to be more stable than satisfaction with life, indicating that the latter is more vulnerable to the influence of external life events. Neuroticism and extraversion emerge as the strongest predictors of life satisfaction (Diener and Lucas 1999; Schimmack et al. 2002), but also conscientiousness is an important predictor (DeNeve and Cooper 1998; Hayes and Joseph 2003).

In a meta-analysis study, DeNeve and Cooper (1998) concluded that personality, despite being a predictor of SWB, only explained $4 \%$ of the variance for all its indices. Nonetheless, Steel et al. (2008) argue that the relation between personality and SWB has been underestimated and results from a meta-analysis conducted by these authors showed that 
personality measured by the Big Five explains a larger percentage of variance in quality of life measures, pointing out to the key role traits play in SWB levels. Additionally, Steel et al. (2008) refer that understanding SWB implies an approach that allows the detailed comprehension of the way personality traits are related with SWB and that requires an approach at the facets level.

\section{The Present Study}

Even though the association between life satisfaction and extraversion and neuroticism facets has already been investigated (Schimmack et al. 2004), it is relevant to broaden this study to other SWB dimensions and to conscientiousness facets. Therefore, we set out to explore the relations between personality and SWB, studying the predictive power of neuroticism, extraversion and conscientiousness facets on each SWB components. Our hypotheses are that there are differences in the way of these facets predict each SWB components and that these facets contribute to explain more variance than the broad-traits.

\section{Method}

\subsection{Participants}

The sample included in this study consisted of 398 teachers (287 woman and 111 men) of primary and high schools from Viseu district (Portugal), randomly selected by clusters corresponding to the schools they worked in. Mean age was 41.09 years (SD = 7.71). The majority of subjects were married, $75.6 \%(N=301)$ and $78.95 \%$ graduated $(N=314)$. The average of years of teaching experience was $16.85(\mathrm{SD}=8.00)$.

\subsection{Procedure}

The first author of this study contacted the schools boards and obtained permission for data collection. With the collaboration of school staff, the author gave participants a battery of self-report questionnaires related to personality and well-being measures and sociodemographic and professional data, as well as script information about the research goals and filling instructions. In line with ethical requirements, it was emphasized that participants cooperation was voluntary and that answers were confidential and only used for the purpose of the study.

\section{Measures}

\subsection{Personality Traits}

Personality traits were measured with self-report version of NEO Personality InventoryRevised (NEO PI-R), that was developed by Costa and McCrae (1992) and validated to Portuguese population by Lima (1997). The integral version includes a 240-item questionnaire that assesses Big Five personality domains (Neuroticism-N, Extraversion-E, Openness to Experience-O, Agreeableness-A, and Conscientiousness-C), as well as 6 
Table 1 Means, standard deviations (SD) for all subjects $N=398$ ) and independent $t$-test for gender differences

\begin{tabular}{|c|c|c|c|c|c|c|c|c|}
\hline & \multicolumn{2}{|l|}{ Total } & \multicolumn{2}{|l|}{ Males } & \multicolumn{2}{|c|}{ Females } & \multirow[t]{3}{*}{$p$} & \multirow[t]{3}{*}{ Cronbach $\alpha$} \\
\hline & \multicolumn{2}{|c|}{$(N=398)$} & \multicolumn{2}{|c|}{$(n=111)$} & \multicolumn{2}{|c|}{$(n=287)$} & & \\
\hline & Mean & SD & Mean & SD & Mean & SD & & \\
\hline Neuroticism & & & & & & & & .91 \\
\hline Anxiety & 19.51 & 4.62 & 18.51 & 4.25 & 19.89 & 4.71 & .007 & .71 \\
\hline Anger & 13.34 & 4.29 & 12.93 & 3.95 & 13.49 & 4.42 & .218 & .70 \\
\hline Depression & 15.20 & 5.39 & 13.92 & 5.06 & 15.69 & 5.44 & .003 & .79 \\
\hline Self-consciousness & 16.69 & 4.16 & 16.24 & 3.70 & 16.87 & 4.31 & .173 & .62 \\
\hline Impulsiveness & 15.98 & 4.36 & 16.67 & 3.88 & 15.72 & 4.51 & .051 & .65 \\
\hline Vulnerability & 12.90 & 4.56 & 11.91 & 4.23 & 13.28 & 4.63 & .007 & .76 \\
\hline Extroversion & & & & & & & & .88 \\
\hline Warmth & 22.44 & 4.9 & 22.08 & 3.52 & 22.57 & 3.81 & .238 & .68 \\
\hline Gregariousness & 17.06 & 4.76 & 16.48 & 4.43 & 17.29 & 4.87 & .127 & .69 \\
\hline Assertiveness & 14.65 & 4.08 & 14.97 & 3.99 & 14.52 & 4.12 & .321 & .62 \\
\hline Activity & 17.86 & 3.62 & 17.38 & 3.81 & 18.04 & 3.95 & .129 & .60 \\
\hline Excitement seeking & 16.46 & 4.06 & 17.63 & 3.91 & 16.00 & 4.03 & .000 & .55 \\
\hline Positive emotions & 20.45 & 5.14 & 20.51 & 4.73 & 20.42 & 5.29 & .873 & .80 \\
\hline Conscientiousness & & & & & & & & .90 \\
\hline Competence & 21.78 & 3.18 & 22.00 & 3.39 & 21.69 & 3.09 & .381 & .61 \\
\hline Order & 20.17 & 5.21 & 18.81 & 5.54 & 20.69 & 4.99 & .001 & .79 \\
\hline Dutifulness & 24.25 & 3.30 & 23.75 & 3.55 & 24.30 & 3.19 & .131 & .57 \\
\hline Achievement striving & 20.81 & 3.90 & 20.42 & 4.39 & 20.96 & 3.69 & .255 & .68 \\
\hline Self-discipline & 20.08 & 4.24 & 19.19 & 4.39 & 20.42 & 4.14 & .009 & .72 \\
\hline Deliberation & 18.76 & 4.16 & 18.46 & 3.77 & 18.87 & 4.30 & .381 & .70 \\
\hline
\end{tabular}

more specific traits facets within each domain. Each facet was measured in a set of 8 items. Answers were given in Likert scale ranging from 0 (strongly disagree) to 4 (strongly agree). Costa, McCrae and Dye (1991) indicated an internal consistency measured by Cronbach's alpha of .92 for N, .89 for E and .90 for C and Lima (1997), with a Portuguese sample, found values in Cronbach's alpha of 85 for $\mathrm{N}, .86$ for $\mathrm{E}$ and .80 for C. In this study, results of internal consistency for these three personality domains and their facets can be observed in Table 1.

\subsection{Subjective Well-Being}

SWB was assessed by two self-report measures: Satisfaction with Life Scale (SWLS) and Positive and Negative Affect Schedule (PANAS).

\subsubsection{SWLS}

SWLS was designed by Diener et al. (1985) and appraises the cognitive component of SWB. The version used in the present study was validated to the Portuguese population by Simões (1992). The scale includes 5 items that evaluate our life satisfaction and the 
Portuguese version was measured on a rating scale from 1 (strongly disagree) to 5 (strongly agree). Diener and colleagues (1985) observed an internal consistency (measured by Cronbach's alpha) of .87, Simões (1992), in a Portuguese sample, found an alpha value of .77 in the same parameter.

\subsubsection{PANAS}

PANAS was developed by Watson et al. (1988) and integrates two subscales, Positive Affect (PA) and Negative Affect (NA) that assess the affective component of SWB and was measured on a rating scale from 1 (very slightly or not of all) to 5 (extremely). Watson et al. (1988) presented an internal consistency of .86-.90 for PA and .84-.87 for NA. Simões (1993), in a first validation to Portuguese population, found a Cronbach's alpha of .82 for PA and .85 for NA.

The Portuguese versions of SWLS (Simões 1992) and PANAS (Simões 1993) used in the present study were validated by Albuquerque et al. (2011) who, using a confirmatory factorial analysis with this same sample, had evidence to accept a three factor model with 5 items in SWLS, 9 items in PA of PANAS and 9 items in NA of PANAS. These authors found a Cronbach's alpha of .84 for SWLS, .79 for PA and .86 for NA.

\section{Results}

Concerning reliability analysis, measures in this study have Cronbach's alphas ranging from .79 (depression and order) to .55 (excitement seeking). Two facets, excitement seeking and dutifulness, were excluded from posterior analysis because their internal consistency indices were lower than the recommended cut point for psychological scales (.60) (Nunnally 1978).

The means and standard deviations for neuroticism, extraversion and conscientiousness facets are presented in Table 1 . We conducted independent $t$-test to explore gender differences in the variables under consideration. Results show that women have statistically significant higher scores in anxiety, depression and vulnerability, as well as in order and self-discipline.

When we compare the current facets' means with the mean values reported in the Portuguese NEO PI R validation (Lima 1997), we find, in general, a similar pattern.

To explore the relationship between neuroticism, extraversion and conscientiousness facets and subjective well-being components, Pearson product-moment correlations were conducted (Table 2).

Results showed statistically significant correlations between the facets of each of the three personality domains and subjective well-being variables (positive affect, negative affect and life satisfaction), with the exception of the relation between impulsiveness and life satisfaction, and activity and achievement striving with negative affect.

Despite these findings, all facets were maintained in the regression models to test the equation with the same predictors for the three constructs of SWB, because this option would enable us to better compare the results.

We conducted multiple regression analyses using neuroticism, extraversion and conscientiousness facets to predict positive affect, negative affect and life satisfaction (Table 3). 
Table 2 Correlations (2-tailed Pearson $r$ ) between neuroticism, extraversion and conscientiousness facets and SWB components

\begin{tabular}{|c|c|c|c|}
\hline Variables & Positive affect & Negative affect & Life satisfaction \\
\hline Neuroticism & $-.41 * *$ & $.66^{* *}$ & $-.39 * *$ \\
\hline Anxiety & $-.32 * *$ & $.54 * *$ & $-.30 * *$ \\
\hline Anger & $-.24 * *$ & $.51 * *$ & $-.24 * *$ \\
\hline Depression & $-.41 * *$ & $.60 * *$ & $-.43 * *$ \\
\hline Self-consciousness & $-.35 * *$ & $.41 * *$ & $-.29 * *$ \\
\hline Impulsiveness & -.10 & $.27 * *$ & -.08 \\
\hline Vulnerability & $-.42 * *$ & $.57 * *$ & $-.42 * *$ \\
\hline Extroversion & $.45^{* *}$ & $-.31 * *$ & $.27 * *$ \\
\hline Warmth & $.36 * *$ & $-.23 * *$ & $.17 * *$ \\
\hline Gregariousness & $.18 * *$ & $-.17 * *$ & $.11^{*}$ \\
\hline Assertiveness & $.48 * *$ & $-.28 * *$ & $.24 * *$ \\
\hline Activity & $.42 * *$ & -.10 & $.18 * *$ \\
\hline Positive emotions & $.45 * *$ & $-.36 * *$ & $.34 * *$ \\
\hline Conscientiousness & $.42 * *$ & $-.31 * *$ & $.28 * *$ \\
\hline Competence & $.38 * *$ & $-.35 * *$ & $.29 * *$ \\
\hline Order & $.19 * *$ & $-.12 *$ & .09 \\
\hline Achievement striving & $.46^{* *}$ & -.10 & $.25 * *$ \\
\hline Self-discipline & $.42 * *$ & $-32 * *$ & $.26^{* *}$ \\
\hline Deliberation & $.17 * *$ & $-.32 * *$ & $.21 * *$ \\
\hline
\end{tabular}

$* * p<.01 ; * p<.05$

Regression analyses were conducted to explore the impact of personality (facets) on SWB. Before this procedure, multiple regression assumptions were assessed (including residuals normality, linearity, homoscedasticity and multicollinearity), and these showed no important constrains to the use of the current data for regression analysis. The results revealed that all facets (predictor variables) produce significant models in each SWB component.

In the first analyses, concerning neuroticism, the six facets of this global trait produce three significant models accounting for $21 \%$ of the variance in positive affect, $44 \%$ in negative affect and $21 \%$ in life satisfaction. Concerning adjusted $R^{2}$ (that makes allowance for the degree of freedom for each model) (Hair et al. 2006), it's possible to see differences in the percentage of variance explained, however these differences are modest. Regarding the specific contribution of the neuroticism facets, we can see that vulnerability, depression and self-consciousness are significant predictors of positive affect. Depression, vulnerability, anger and anxiety make a statistical significant contribution to the prediction of negative affect. The significant predictors for life satisfaction are depression and vulnerability.

In relation to extraversion facets, all three regression models have a significant impact on the prediction of SWB accounting for $31 \%$ of the explained variance in positive affect, $17 \%$ in negative affect and $12 \%$ in life satisfaction with a slight decrease in adjusted $R^{2}$. The regression coefficients analysis reveals a significant impact of assertiveness, positive emotions and activity facets as predictors of positive affect. In the prediction of negative affect the significant facets are positive emotions, assertiveness and activity. Positive emotions are the only facet with statistically significant positive impact on life satisfaction. 


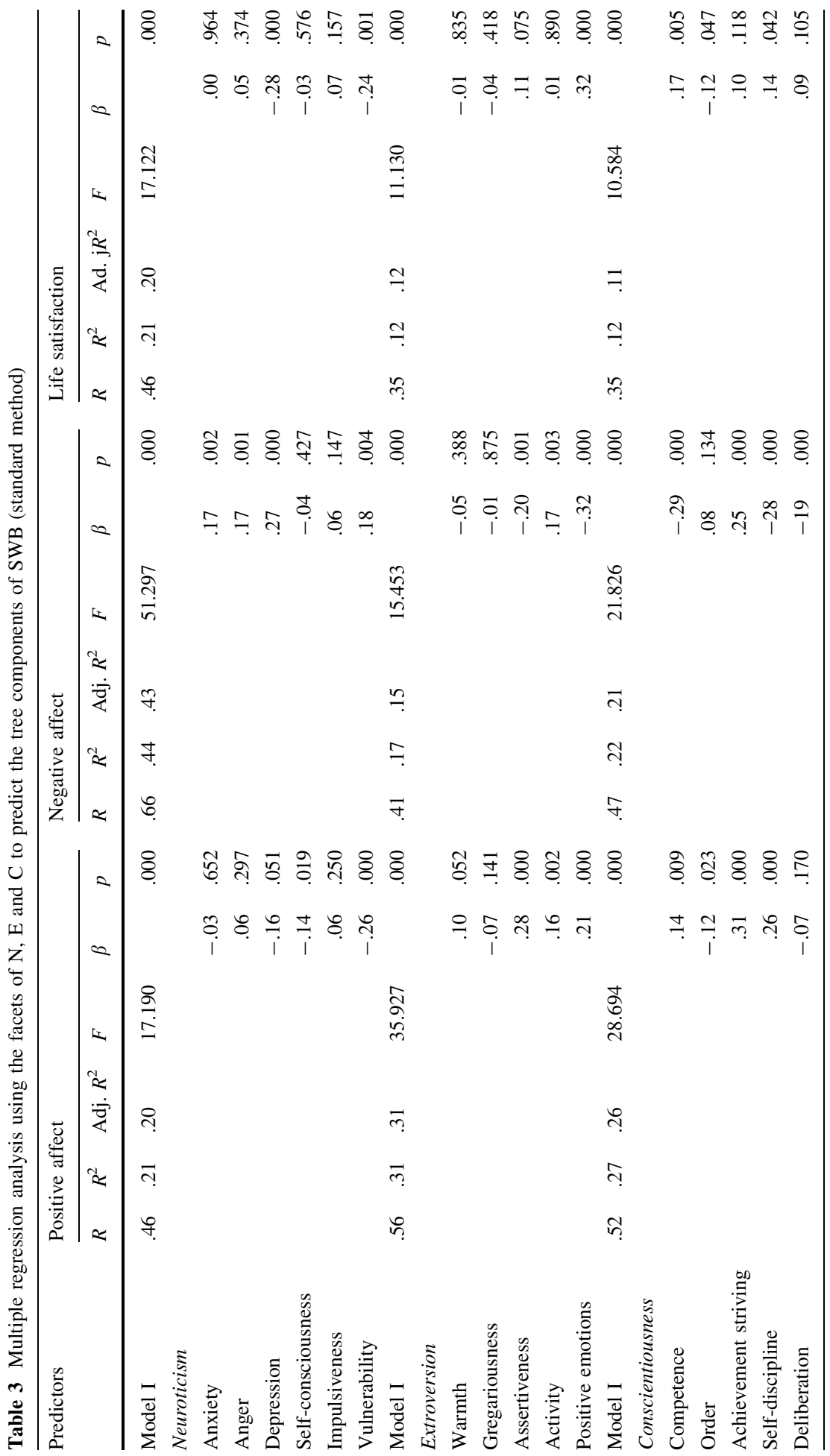


The five conscientiousness facets also produced three significant models, accounting for different amounts of variance explained in the three SWB components, as reported above. So, the conscientiousness facets contribute to explain $27 \%$ of variance in positive affect, $22 \%$ in negative affect and $12 \%$ in life satisfaction. The differences between $R^{2}$ and adjusted $R^{2}$ are small. In positive affect prediction, achievement striving, self-discipline, competence and order emerged as significant predictors. In the prediction of negative affect, the facets which have a significant impact are competence, self-discipline, achievement striving and deliberation. All show the particularity of having a negative impact in negative affect apart from achievement striving. The life satisfaction criterion has as statistically significant predictors three facets: competence, self-discipline and order.

In order to compare the impact of personality factors at a global level with the impact of the respective set of facets in SWB prediction, we conducted linear regression analyses using each global personality factor as predictors. All regression models were statistically significant. Neuroticism factor explained $17 \%$ of the variance in positive affect $(R=.41$; $R^{2}=.17$; Adj. $\left.R^{2}=.16 ; F_{(1,396)}=77.986 ; p<.001\right), 42 \%$ of the variance in negative affect $\left(R=.65 ; R^{2}=.42\right.$; Adj. $\left.R^{2}=.41 ; F_{(1,396)}=281.565 ; p<.001\right)$, and $15 \%$ of life satisfaction variance $\left(R=.39 ; R^{2}=.15 ;\right.$ Adj. $\left.R^{2}=.15 ; F_{(1.396)}=71.143 ; p<.001\right)$. Extraversion factor accounted for $25 \%$ of the variance in positive affect $(R=.50$; $R^{2}=.25$; Adj. $\left.R^{2}=.25 ; F_{(1,396)}=131.281 ; p<.001\right), 10 \%$ of the variance in negative affect $\left(R=.31 ; R^{2}=.10\right.$; Adj. $\left.R^{2}=.10 ; F_{(1,396)}=42.811 ; p<.001\right)$, and $8 \%$ of the variance in life satisfaction $\left(R=.27 ; R^{2}=.08 ;\right.$ Adj. $R^{2}=.07 ; \quad F_{(1,396)}=31.898$; $p<.001)$. Conscientiousness factor contributed to $18 \% \quad\left(R=.42 ; R^{2}=.18 ;\right.$ Adj. $\left.R^{2}=.17 ; F_{(1,396)}=84.107 ; p<.001\right)$ of the variance explanation in positive affect, $10 \%$ of negative affect explained variance $\left(R=.31 ; R^{2}=.10 ;\right.$ Adj. $R^{2}=.10 F_{(1,396)}=42.709$; $p<.001)$, and $8 \%$ of the variance explained in life satisfaction $\left(R=.28 ; R^{2}=.08\right.$; Adj. $\left.R^{2}=.07 ; F_{(1,396)}=32.569 ; p<.001\right)$. In all cases, and comparing adjusted $\mathrm{R}^{2 \mathrm{~s}}$, the regression models using the set of facets as predictors explain more variance in SWB components, than the regression models using the respective global personality factors as independent variables.

\section{Discussion}

Despite the existence of several studies about the relation between personality and subjective well-being, the knowledge concerning the specific influences of facets in subjective well-being or its components remains modest. The present study aimed at exploring the relations between neuroticism, extraversion and conscientiousness facets and each SWB components. Our hypothesis that there were differences in the way these facets predict each SWB components was confirmed. Additionally, neuroticism, extraversion and conscientiousness facets contribute to explain more variance than the corresponding traits at a global level, giving support to our second hypothesis.

The findings confirm that all sets of facets (neuroticism, extraversion, and conscientiousness) influence the three SWB components. However, there are considerable differences in the magnitude of the variance explained by each set. Neuroticism facets are those that better explained negative affect but also explained substantial and similar variance both in positive affect and life satisfaction. Extraversion facets explained especially the positive affect while conscientiousness facets explained positive and negative affect almost at same level. Life satisfaction is the SWB component whose variance is explained by either extraversion facets or conscientiousness at a lower level. Our results corroborated, at 
the facets level, findings of several researches that pointed neuroticism as the strongest predictor of negative affect, whereas extraversion predicts strongly positive affect (Argyle 1999; Cheng and Furnham 2001; Diener and Lucas 1999; Fujita 1991; Gutiérrez et al. 2005; McCrae and John 1992; Vitters $\varnothing$ and Nilsen 2002). Concerning life satisfaction, several studies suggest that neuroticism and extraversion are also its strongest predictors (Diener and Lucas 1999; Schimmack et al. 2002). The current findings partially corroborate this conclusion at a facets level, since conscientiousness facets predict life satisfaction almost the same level as extraversion facets. Finally, as some authors refer concerning to factor level (DeNeve and Cooper 1998; Hayes and Joseph 2003), conscientiousness at a facets level emerges as a considerable predictor of the three SWB components.

Facets are supposed to reflect a discrete trait and, according to Costa and McCrae (2008), to contribute something above and beyond the five factors. Steel et al. (2008) pointed that, mathematically, in the relationship between personality facets and SWB, three events could occur that would affect the total variance accounted for at a global trait: only some variables are related to SWB; all variables are pertinent; or variables within same global trait may have correlations with inverse direction. The results of the present study support the first and the third event, but not the second.

Actually, the fact that in all regression models not all facets appear as significant predictors in SWB, could reveal that there are facets within the set that may be irrelevant and only be adding "error" in the equation. Nevertheless, these findings should be carefully interpreted since different facets predict distinct SWB components: anxiety $(\mathrm{N})$, and anger $(\mathrm{N})$ only predict negative affect, self-consciousness $(\mathrm{N})$ only predicts positive affect, or deliberation $(C)$ that just predicts negative affect. Only four facets predict all three SWB components: vulnerability $(\mathrm{N})$, positive emotions (E) competence $(\mathrm{C})$ and self-discipline (C). Furthermore, there are facets within de same personality domain, and despite the positive correlations between them, predict the same SWB component in opposite direction: activity (E) predicts positively negative affect, order (C) predicts inversely positive affect and life satisfaction, and achievement striving predicts positively negative affect. An intriguing finding is the positive predictive impact of achievement striving on the prediction of positive affect and negative affect. Studies related to the influence of facets in each SWB components are scarce, nonetheless Schimmack et al. (2004) found that depression (N) and positive emotions (E) were the strongest and most consistent predictors of life satisfaction. Our results are consistent with these but, in our study, vulnerability (N) also emerges as a strong predictor of life satisfaction. Our data does not support the Vitters $\varnothing$ and Nilsen (2002) findings that suggested neuroticism contributes with all its six facets and extraversion is weaker since it is mainly represented by its positive emotions facet.

These results concerning the predictive value of personality facets in SWB components support the idea formulated by Costa and McCrae (2008) that facets can explain more than factors since they contain valid specific variance, (i.e. meaningful individual differences are unrelated to the common factors).

In addition, regarding SWB components, our results reinforce the independence of positive affect, negative affect and life satisfaction found in other study concerning SWB structure (Albuquerque et al. 2011); Arthaud-Day et al. 2005; Lucas et al. 1996). In fact, it is possible to observe a clear and distinctive pattern of correlations in each SWB component: neuroticism facets correlate positively to negative affect and inversely to positive affect and life satisfaction, whereas extraversion and conscientiousness facets are inversely correlated with negative affect and positively with positive affect and life satisfaction. 
Similarly, in general, facets showed specific predictive power depending on the SWB component used as dependent variable.

Additionally, the current study supports the idea that the variance explained by the set of facets is higher than the variance explained by the global factor at SWB components level. So, these results corroborated the findings of several studies that suggest facets improve the prediction of several variables (Ekehammar and Akrami 2007; Paunonen and Ashton 2001; Paunonen et al. 2003; Reynolds and Clark 2001).

Two major implications can be drawn from the study of the relations between personality and subjective well-being. The first is that a comprehensive understanding of these relations requires a detailed evaluation at a facet level, since facets predict each SWB component with relative specificity. Effectively, if the three personality domains (neuroticism, extraversion and conscientiousness) are relevant for the explanation of each SWB component, their facets have indeed a specific and differentiated role in explaining their variance. The second is the need of a complete SWB assessment that includes all three components, because if the study of the personality impact focuses merely on one SWB component, it may lead to an incomplete and biased view of this relation. As authors stated, cognitive and affective components seem to be influenced by distinct factors (Schimmack 2006) and differently by the same factors (Schimmack et al. 2002).

\section{Limitations and Future Research}

One methodological limitation of our study concerns the specificity of the population studied composed only by teachers. Since the overrepresentation of certain groups limits the generalization to other populations (Brewer 2000), additional studies should be developed using larger and heterogeneous samples.

The cross-sectional design of the study doesn't allow drawing conclusions about the interrelationship between the facets across time or establishing if there is a causal effect between predictor variables. Longitudinal studies can help to overcome this problem.

The present study merely explores the direct effects of facets on each SWB component. However, we know that traits, either factors or facets, are only one level of personality analysis and that an holistic understanding of the relations between personality and SWB should considerer the personality as whole (Little 1996, 2008; McAdams 1995, 1996; McAdams and Olson 2010; McAdams and Pals 2006; McCrae and Costa 1996, 2008; Sheldon 2004). Future research should explore the moderator and mediator influences of personality variables from other levels in the relation between traits and each SWB component. Lucas (2008) refers that personality is relevant, but it is important to know precisely what processes underlie these effects.

\section{Conclusion}

The current study clarifies the relationships between personality and SWB and contributes to reduce the ambiguity in this realm. Results substantiate that the understanding of relations between personality and subjective well-being implies the need of analyses at a detailed level of personality and SWB, since that can help us understand how personality traits are related to each specific SWB component. Our findings suggest that facets, within the same personality domain, predict differentially each of the three SWB components and 
this corroborates, at same time, two important premises: the specificity of facets as discrete traits and the independence of the three SWB components. Additionally, this study supports the premise that facets explain more variance than personality factors.

\section{References}

Albuquerque, I., Lima, M. P., Figueiredo, C., \& Matos, M. (2011). Subjective well-being structure: Confirmatory factor analysis in a Portuguese teacher sample.

Argyle, M. (1999). Causes and correlates of happiness. In D. Kahneman, E. Diener, \& N. Schwarz (Eds.), Well-being: The foundations of hedonic psychology (pp. 213-229). New York: Russell Sage Foundation.

Arthaud-Day, M. L., Rode, J. C., Mooney, C. H., \& Near, J. P. (2005). The subjective well-being construct: A test of its convergent, discriminate, and factorial validity. Social Indicators Research, 74, 445-476.

Bartels, M., \& Boomsma, D. I. (2009). Born to be happy? The etiology of subjective well-being. Behavior Genetics, 39, 605-615.

Brewer, M. B. (2000). Research design and issues of validity. In H. T. Reis \& C. M. Judd (Eds.), Handbook of research methods in social and personality psychology (pp. 3-16). Cambridge: Cambridge University Press.

Cheng, H., \& Furnham, A. (2001). Attributional style and personality as predictors oh happiness and mental health. Journal of Happiness Studies, 2, 307-327.

Costa, P. T., Jr, \& McCrae, R. R. (1980). Influence of extraversion and neuroticism n subjective well-being. Happy and unhappy people. Journal of Personality and Social Psychology, 38, 668-678.

Costa, P. T., Jr, \& McCrae, R. R. (1992). Revised NEO personality inventory (NEO-PI-R) and NEO fivefactor inventory (NEO-FFI). Odessa, FL: Psychological Assessment Resources, Inc.

Costa, P. T., Jr, \& McCrae, R. R. (1994). Set like plaster? Evidence for the stability of adult personality. In T. F. Heatherton \& J. L. Weinberger (Eds.), Can personality change? (pp. 21-40). Washington, DC: American Psychological Association.

Costa, P. T., Jr, \& McCrae, R. R. (2008). The revised NEO personality inventory (NEO-PI-R). In G. J. Boyle, G. Matthews, \& D. H. Saklofske (Eds.), The Sage book of personality theory and assessment (Vol. 2, pp. 179-198). London: Sage Publications.

Costa, P. T., Terracciano, A., \& McCrae, R. R. (2001). Gender differences in personality traits across cultures: Robust and surprising findings. Journal of Personality and Social Psychology, 81, 322-331.

Deci, E. L., \& Ryan, R. M. (2008). Hedonia, eudaimonia, and well-being: An introduction. Journal of Happiness Studies, 9, 1-11.

DeNeve, K. M., \& Cooper, H. (1998). The happy personality: A meta-analysis of 137 personality traits and subjective well-being. Psychological Bulletin, 95, 542-575.

Diener, E. (2000). Subjective well-being: The science of happiness and proposal for a national index. American Psychologist, 55, 34.

Diener, E., Emmons, R. A., Larsen, R. J., \& Griffin, S. (1985). The satisfaction with life scale. Journal of Personality Assessment, 49, 71-75.

Diener, E., \& Lucas, R. E. (1999). Personality and subjective well-being. In D. Kahneman, E. Diener, \& N. Schwarz (Eds.), Well-being: The foundations of hedonic psychology (pp. 213-229). New York: Russell Sage Foundation.

Diener, E., Lucas, R. E., \& Oishi, S. (2005). Subjective well-being: The science of happiness and life satisfaction. In C. R. Snyder \& S. J. Lopez (Eds.), Handbook of positive psychology (pp. 63-73). New York: Oxford University Press.

Diener, E., Suh, E. M., Lucas, R. E., \& Smith, H. L. (1999). Subjective well-being: Tree decades of progress. Psychological Bulletin, 125, 276-302.

Ekehammar, B., \& Akrami, N. (2007). Personality and prejudice. From big five personality factors to facets. Journal of Personality, 75, 899-925.

Fujita, F. (1991). An investigation of the relation between extraversion, neuroticism, positive affect, and negative affect. Unpublished master's thesis, University of Illinois, Urbana Champaign.

Fujita, F., \& Diener, E. (2005). Life satisfaction set point: Stability and change. Journal of Personality and Social Psychology, 88, 158-164.

Golberg, L. R. (1990). An alternative "description of personality": The big five factor structure. Journal of Personality and Social Psychology, 59, 1216-1229.

Golberg, L. R. (1993). The structure of phenotypic personality traits. American Psychologist, 48, 26-34. 
Gutiérrez, J. L. G., Jiménez, B. M., Hernandez, E. G., \& Puente, C. P. (2005). Personality and subjective well-being: Big five correlates and demographic variables. Personality and Individual Differences, 38, 1561-1769.

Hair, J., Black, W., Babin, B., Anderson, R., \& Tatham, R. (2006). Multivariate data analysis (6th ed.). New Jersey: Pearson Prentice Hall.

Hayes, N., \& Joseph, S. (2003). Big 5 correlates of tree measures of subjective well-being. Personality and Individual Differences, 34, 723-727.

Hooker, K., \& McAdams, D. P. (2003). Personality reconsidered: A new agenda for aging research. The Journal of Gerontology, 58B(6), 296-304.

John, O. P., \& Srivastava, S. (1999). The big five traits taxonomy: History measurement, and theoretical perspectives. In L. Pervin \& O. P. John (Eds.), Handbook of personality: Theory and research (2nd ed., pp. 102-138). New York: Guilford Press.

Lima, M. P. (1997). NEO-PI-R: Contextos teóricos e psicométricos. “Ocean” ou "iceberg”. (Unpublished doctoral dissertation). University of Coimbra, Coimbra.

Little, B. R. (1996). Free traits, personal projects and idio-tapes: Three tiers for personality psychology. Psychological Inquiry, 7, 340-344.

Little, B. R. (2008). Personal projects and free traits: Personality and motivation reconsidered. Social and Personality Compass, 2, 1235-1254.

Little, B. R., \& Joseph, M. F. (2007). Personal projects and free traits: Mutable selves and well-beings. In B. R. Little, K. Salmela-Aro, \& S. D. Phillips (Eds.), Personal projects pursuit: Goals, action, and human flourishing (pp. 375-400). New Jersey: Lawrence Erlbaum Associates Publishers.

Lucas, R. E. (2008). Personality and subjective well-being. In M. Eid \& R. J. Larsen (Eds.), The science of subjective well-being (pp. 171-194). New York: The Guilford Press.

Lucas, R. E., Diener, E., \& Suh, E. (1996). Discriminant validity of well-being measures. Journal of Personality and Social Psychology, 71, 616-628.

Lucas, R. E., \& Fujita, F. (2000). Factors influencing the relation between extraversion and pleasant affect. Journal of Personality and Social Psychology, 79, 1039-1056.

Lykken, D. (1999). Happiness: What studies of twins show us about nature, nurture, and the happiness setpoint. New York: Golden Books.

Lykken, D. T., \& Tellegen, A. (1996). Happiness is stochastic phenomenon. Psychological Science, 7, $186-189$.

Lyubomirsky, S., Sheldon, K. M., \& Schkade, D. (2005). Pursuing happiness: The architecture of sustainable change. Review of General Psychology, 9, 111-131.

McAdams, D. P. (1995). What do we know when we know a person? Journal of Personality, 63, 365-393.

McAdams, D. P. (1996). Personality, modernity, and storied self: A contemporary framework for studying persons. Psychological Inquiry, 7, 295-321.

McAdams, D. P., \& Olson, B. D. (2010). Personality development: Continuity and change over the life course. Annual Review of Psychology, 61, 517-542.

McAdams, D. P., \& Pals, J. L. (2006). A new big five: Fundamental principles for an integrative science of personality. American Psychologist, 61, 204-217.

McCrae, R. R., \& Costa, P. T., Jr. (1996). Toward a new generation of personality theories: Theoretical contexts for the five-factor model. In J. S. Wiggins (Ed.), The five-factor model of personality: Theoretical perspectives (pp. 51-87). New York: Guilford Press.

McCrae, R. R., \& Costa, P. T., Jr. (1997). Personality trait structure as human universal. American Psychologist, 52, 509-516.

McCrae, R. R., \& Costa, P. T., Jr. (2003). Personality in adulthood: A five-factor theory perspective (2nd ed.). New York: Guilford Press.

McCrae, R. R., \& Costa, P. T., Jr. (2008). Empirical and theoretical status of the five-factor model of personality traits. In G. J. Boyle, G. Matthews, \& D. H. Saklofske (Eds.), The Sage book of personality theory and assessment (Vol. 1, pp. 272-293). London: Sage Publications.

McCrae, R. R., Costa, P. T., Jr., Lima, M. P., Simões, A., Ostendorf, F., Angleitner, A., et al. (1999). Age differences in personality across the adult lifespan: Parallels in five cultures. Developmental Psychology, 35, 466-477.

McCrae, R. R., \& John, O. P. (1992). An introduction to the five-factor model and its applications. Journal of Personality, 60, 175-216.

Nunnally, J. C. (1978). Psychometric theory (2nd ed.). New York: McGraw-Hill.

Ozer, D. J., \& Benet-Martínez, V. (2006). Personality and prediction of consequential outcomes. Annual Review of Psychology, 57, 401-421.

Paunonen, S., \& Ashton, M. C. (2001). Big five factors and facets and the prediction of behaviour. Journal of Personality and Social Psychology, 81, 524-539. 
Paunonen, S. V., Haddock, G., Forsterling, F., \& Keinonen, M. (2003). Broad versus narrow personality measures and prediction of behaviour across cultures. European Journal of Personality, 17, 413-433.

Pavot, W., Fujita, F., \& Diener, E. (1995). The relation between self-aspect congruence, personality and subjective well-being. Personality and Individual Differences, 22, 183-191.

Reynolds, S. K., \& Clark, L. A. (2001). Predicting dimensions of personality disorder from domains and facets of five factor model. Journal of Personality, 69, 199-222.

Roberts, B. W. (2009). Back to the future: Personality and assessment and personality development. Journal of Research in Personality, 43, 137-145.

Schimmack, U. (2006). The structure of subjective well-being: Personality, affect, life satisfaction, and domain satisfaction. Unpublished manuscript.

Schimmack, U., Diener, E., \& Oishi, S. (2002). Life-satisfaction is a momentary judgment and a stable personality characteristic: The use of chronically accessible and stable sources. Journal of Personality, 70, 345-384.

Schimmack, U., Oishi, S., Furr, R. M., \& Funder, D. C. (2004). Personality and life satisfaction. Personality and Social Psychological Bulletin, 30, 1062-1075.

Sheldon, K. M. (2004). Optimal human being: An integrated approach. New Jersey: Lawrence Erlbaum Associates.

Sheldon, K. M., \& Lyubomirsky, S. (2004). Achieving sustainable new happiness: Prospects, practices, and prescriptions. In P. A. Linley \& S. Joseph (Eds.), Positive psychology in practice (pp. 127-145). New Jersey: John Wiley \& Sons.

Simões, A. (1992). Ulterior validação de uma escala de satisfação com a vida (SWLS). Revista Portuguesa de Pedagogia, XXVI(3), 503-515.

Simões, A. (1993). São os homens mais agressivos que as mulheres? Revista Portuguesa de Pedagogia, XXVII, 387-404.

Steel, P., Schmidt, J., \& Shultz, J. (2008). Refining the relationship between personality and subjective wellbeing. Psychological Bulletin, 134, 138-161.

Vitters $\varnothing$, J., \& Nilsen, F. (2002). The conceptual and relational structure of subjective well-being, neuroticism, and extraversion: Once again, neuroticism is the important predictor of happiness. Social Indicators Research, 57, 89-118.

Watson, D., Clark, L., \& Tellegen, A. (1988). Development and validation of brief measures of positive and negative affect: The PANAS scales. Journal of Personality and Social Psychology, 54, 1063-1070.

Weiss, A., Bates, T., \& Luciano, M. (2008). Happiness is a personal(ity) thing: The genetics of personality and well-being in a representative sample. Psychological Science, 19, 205-210. 